\title{
Design of Class E Power Amplifier for Wireless Communication
}

\author{
Dina Riydh Ibrahim, Rusul Amer Abdul Jabbar, Zaid Mamon Ezalden and Ameen Thaer Abdullah \\ dina.ibrahim@uoninevah.edu.iq,rorojabory@gmail.com,zaidmamon99@gmail.com, \\ amin.thaer1997@gmail.com \\ Department of Communication - Electronic Engineering - Ninevah University, Iraq
}

\begin{abstract}
The power amplifier is one of the challenging blocks in the implementation of the handset of wireless communication transceivers. In optimum class E, the drain voltage drops to zero and has zero slopes just as the transistor turns on which result is an ideal efficiency of $100 \%$, reduction of switching losses and increase tolerance of component variation. The proposed class E power amplifier using (MOSFET mf_phi_LF2802A_19930106), (FET_GaAs_fll101_me19931021) and (BJT_BC_32719961209) transistors have been designed in the frequency range of (300MHz-1.5GHz) and note the change in efficiency and power delivered to the load between these types of transistors.
\end{abstract}

Keyword: class E, power amplifier, switch, efficiency

\section{Literature review:}

In 2010 [1] "designed class-E amplifier in CMOS at freq. $900 \mathrm{MHz}$. The power is delivered to a $50 \Omega$ load from a 2.2 V supply and achieved a maximum Power Added Efficiency (PAE) of 43\%". In 2013 [2] "designed two class-E circuits using the GaN (HEMT) in both( infinite DC-feed, shunt inductor conf.) .in infinite dc-feed $69 \%$ drain eff., $64 \%$ PAE, and $21.46 \mathrm{dBm}$ load power, in the case of shunt indictor design $71 \%$ eff., $64.5 \%$ PAE, and $15.93 \mathrm{dBm}$ load power". In 2015 [3] " designed, constructed, and tested class-E power amplifier of $1 \mathrm{MHz}$ operating frequency to generate (PWM) switching signal and drive the IRF510 MOSFET microcontroller board with PIC16F877A is used, with output power 9.45W and drain efficiency of 98.44\%". In 2016 [4] "observed performance parameters relationships to the load and duty cycle with $12 \mathrm{~V}$ dc and efficiency of $98.44 \%$ powered, at $50 \%$ duty cycle and $1 \mathrm{MHz}$ to produce a stable sinusoidal signal". In 2016 [5] " simulated power amplifier by (ADS) CMOS simulation results from $1.8 \mathrm{~V}$ supply voltage at $2.4 / 5.15 \mathrm{GHz}, 21.407 / 21.523 \mathrm{dBm}$ output power to $50 \Omega$ standard load with 55.1/51.07\% Power-Added-Efficiency (PAE) and drain efficiency (DE) 55.5/51.4 \%". In 2016 [6] "designed class E power amplifier operates to a broadband range of $6.78 \mathrm{MHz}-2.45 \mathrm{GHz}$ which achieved by low power and high power transistor. By increasing the order of (input-output) matching network the Efficiency of the power amplifier is increased. A GaN-HEMT transistor is used for the high power, GaAs HBT is used for low power design". In 2017[7] " designed class $\mathrm{E}$ use device of RF3931GaN HEMT in the frequency range of $1 \mathrm{GHz}$, to increasing gain up to $14.327 \mathrm{~dB}$ and achieving high output power and operates. The designed Power Added Efficiency (PAE) is 64\% after maximum source power achieved is 32dBw". In 2018 [8] "presented a power amplifier with single-stage and 2-stage $2.4 \mathrm{GHz}$, the simulated gain and power added efficiency (PAE) for single stage PA are $17.58 \mathrm{~dB}$ and $53 \%$, correspondingly. While the experimental gain and PAE are $16.7 \mathrm{~dB}$ and $49.5 \%$. Conversely, for 2-stages PA, the simulated gain comes out to be $34.6 \mathrm{~dB}$ and PAE is $55 \%$, whereas the experimental gain and PAE are $30.5 \mathrm{~dB}$ and $53.1 \%$, respectively". 


\section{Introduction:}

"Class E power amplifiers can provide power at a theoretical efficiency of $100 \%$ at the expense of linearity. Therefore they are most suitable for systems using constant envelope modulation schemes such as GSM. Class-E full differential amplifier designed in $0.35 \mu \mathrm{m}$ CMOS process. The differential implementation provides twice the voltage swing across the load compared to a single-ended amplifier which results in a four-time increase in output power delivered "[1]. "The saturation mode of the transistor allows it to operate as a switch so either voltage or current (depending on amplifier class) is switched on and off. To be specific, the switch is "on" for almost half of the ac period and "off" for the remainder of the period. A low pass or bandpass filter may be included at the load network to may transform the load impedance and accommodate load reactance and suppress harmonics of the switching frequency at the load" [3]. "Class-E power amplifier offers wonderful advantages and has attracted a great deal of attention in recent years. After that, to expand the applications of the class E circuit, various topologies have appeared such as class E (DC/DC) converter, inverter and rectifier. Also, the class E circuits are applied to RF power amplifier, induction heating system and RF power" [4]. "The implementation of multi-band systems is a very important issue for the next generation of wireless communication. While base-band and analog circuits can be integrated within a single chip for multi-band polar transmitters without significant problem. Wireless connectivity in portable applications demands highefficiency RF transmitters to save battery life. The class E power amplifier is a single switch connection they have ON and OFF switch, the switches should be connected in the load network, because to reduce the power dissipation, if that decreases automatically, the output power should increase and also the efficiency and the main aim is to reduce the size by using the class E power amplifier, theoretically which gives $100 \%$ efficiency" [7].

\section{Switch mode of class $\mathbf{E}$ power amplifier :}

"The point of use transistor operates on a saturation region is to take advantage of switch-mode of either voltage or current on and off. Figure 1 is a block diagram of a single-ended switch-mode amplifier" [3]. "The class E amplifier is designed to provide high efficiency, and it is typically used at high frequencies. An inductor is used in class E power amplifier design to connect to the supply, and a shunting capacitance across the switch to decrease the power loss and shape the standard waveforms for both current and voltage" [6].
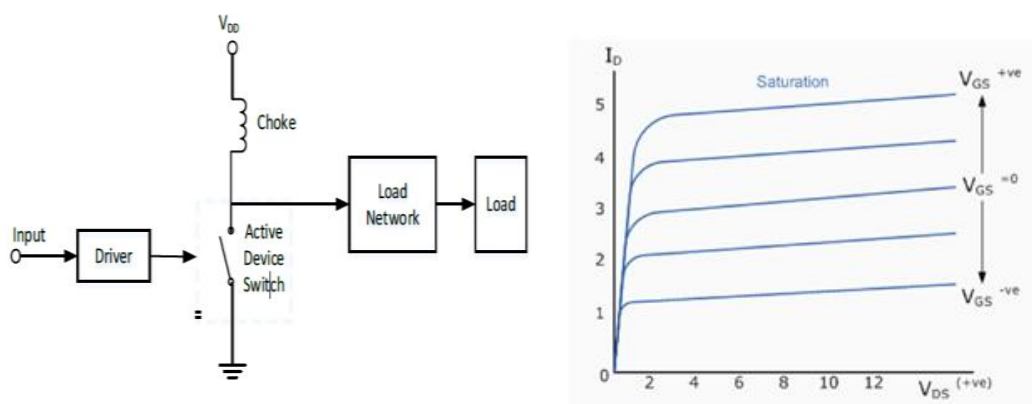

Fig. 1. Switch-mode class E Block Diagram and output characteristic

\section{Simulation and Design of Proposed Power Amplifiers:}

The proposed class E power amplifier is designed using three types of transistors (BJT-FET - MOSFET) to compare the efficiency and power in the same range of frequency. A conventional Class-E amplifier as shown in Figure(2) consists of a transistor with a shunt capacitor C1 present at its output when it is increased, the output current increased also and when it decreases the output voltage increases. The output 
load RL is connected via a series LC filter tuned at the frequency of operation fo. DC power supply VDD is connected to the drain of the transistor via an RF choke L1. The presence of the series LC filter ensures that only the fundamental harmonic current will flow through the load. "This means that the total current through the transistor and the shunt capacitor is the sum of the ac and dc currents through the load and the choke respectively"[1]. "To find the value of power amplifier efficiency the main parameters needed are DC input voltage, DC input current, output voltage and output current" [8].

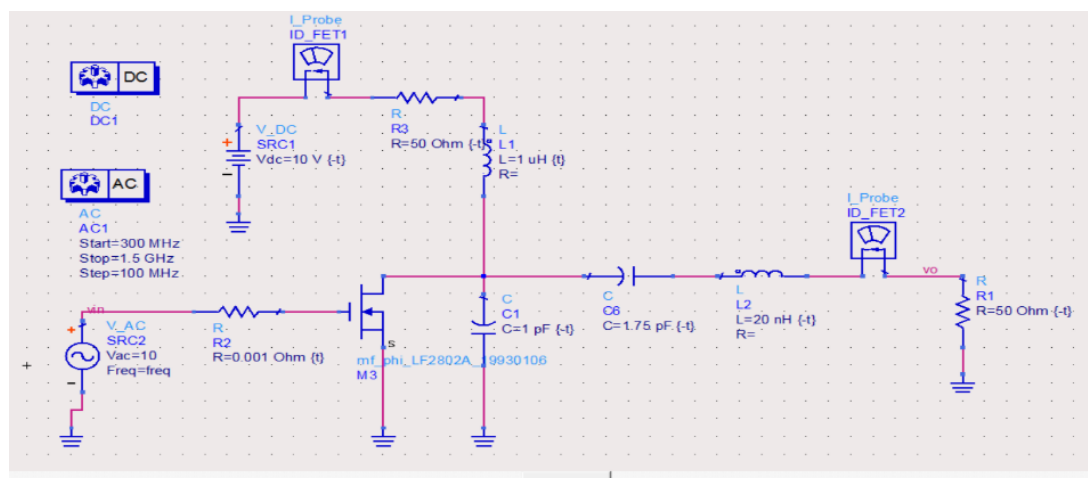

Fig. 2. Proposed Power Amplifier circuit diagram in ADS

5 Results: The circuit in figure (2) illustrates the design of class E power amplifier, the first circuit designed using (MOSFET mf_phi_LF2802A_19930106) ADS, Iout, Vout, Idc are measured and Pout, Pdc and eff\% are calculated as follow

$$
\begin{aligned}
& P_{\text {out }}=V_{\text {out }} * I_{\text {out }} \\
& P_{d c}=V_{d c} * I_{d c} \\
& E f f=\frac{P_{\text {out }}}{P_{d c}}
\end{aligned}
$$

And dc voltage is set to $V_{d c}=11 v$

While DC is measured $I_{d c}=174.3 \mathrm{~mA}$

Table (1) shows measured and calculated values for the frequency range $(300 \mathrm{MHz}-1.5 \mathrm{GHz})$ for (MOSFET mf_phi_LF2802A_19930106) transistor, where figures ( 3 through 6) illustrate the graphs of Efficiency, output AC current, output $\mathrm{AC}$ voltage and output $\mathrm{AC}$ power of the chosen transistor, the figures indicate that the maximum values are at a frequency $(1.3 \mathrm{GHz})$ with $\mathrm{BW}=300 \mathrm{MHz}$.

Table 1. Measured and calculated values for MOSFET mf_phi_LF2802A_19930106

\begin{tabular}{|c|c|c|c|c|c|c|c|}
\hline EFF & PDC & IDC & VDC & POUT & VOUT & IOUT & F \\
\hline 0.000367 & 1.9184 & 0.1744 & 11 & 0.000704 & 0.176 & 0.004 & 300 \\
\hline 0.000951 & 1.9184 & 0.1744 & 11 & 0.001824 & 0.304 & 0.006 & 400 \\
\hline 0.002685 & 1.9184 & 0.1744 & 11 & 0.00515 & 0.515 & 0.01 & 500 \\
\hline 0.007683 & 1.9184 & 0.1744 & 11 & 0.014739 & 0.867 & 0.017 & 600 \\
\hline 0.020638 & 1.9184 & 0.1744 & 11 & 0.039592 & 1.414 & 0.028 & 700 \\
\hline 0.045823 & 1.9184 & 0.1744 & 11 & 0.087906 & 2.093 & 0.042 & 800 \\
\hline
\end{tabular}




\begin{tabular}{|l|c|c|c|c|c|c|c|}
\hline 0.078784 & 1.9184 & 0.1744 & 11 & 0.15114 & 2.748 & 0.055 & 900 \\
\hline 0.126908 & 1.9184 & 0.1744 & 11 & 0.24346 & 3.478 & 0.07 & 1000 \\
\hline 0.233984 & 1.9184 & 0.1744 & 11 & 0.448875 & 4.725 & 0.095 & 1100 \\
\hline 0.554502 & 1.9184 & 0.1744 & 11 & 1.063756 & 7.286 & 0.146 & 1200 \\
\hline 0.751725 & 1.9184 & 0.1744 & 11 & 1.44211 & 8.483 & 0.17 & 1300 \\
\hline 0.275862 & 1.9184 & 0.1744 & 11 & 0.529214 & 5.138 & 0.103 & 1400 \\
\hline 0.110558 & 1.9184 & 0.1744 & 11 & 0.212095 & 3.263 & 0.065 & 1500 \\
\hline
\end{tabular}

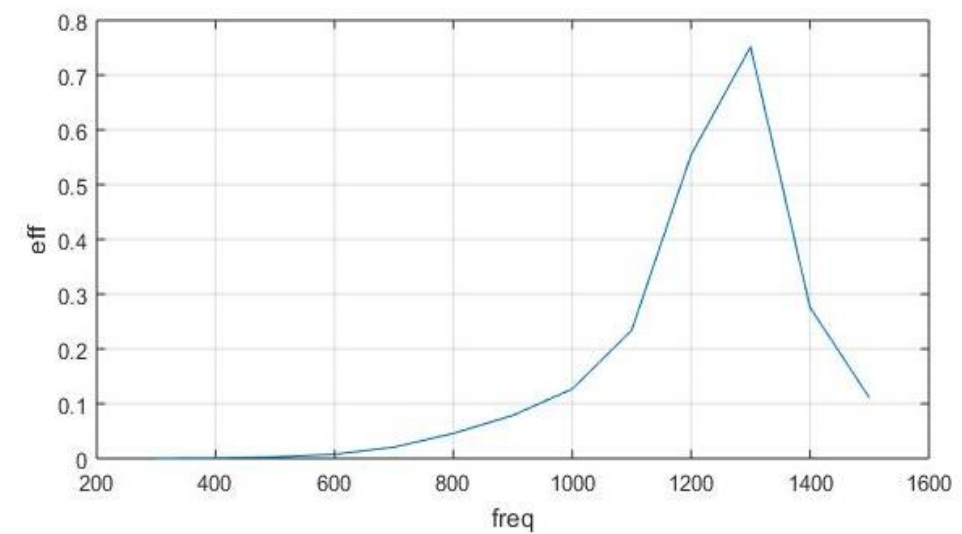

Fig. 3. Efficiency with frequency for MOSFET mf_phi_LF2802A_19930106

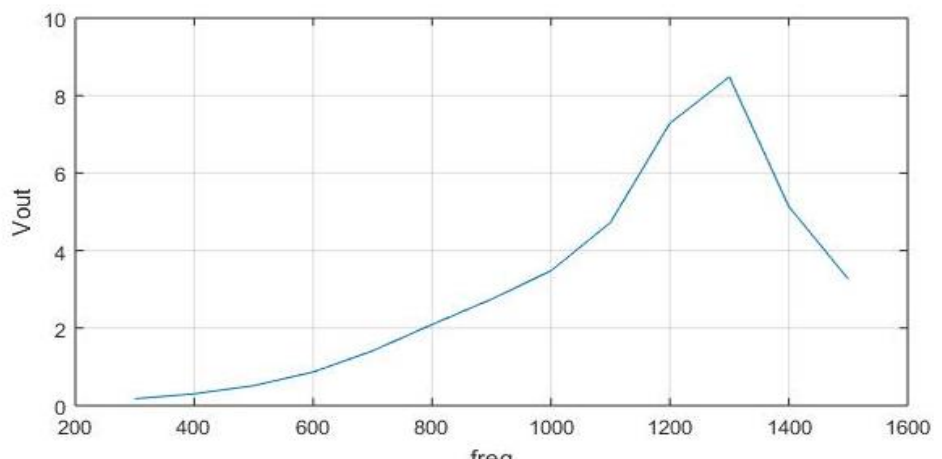

Fig. 4. Output AC current with frequency for MOSFET mf_phi_LF2802A_19930106

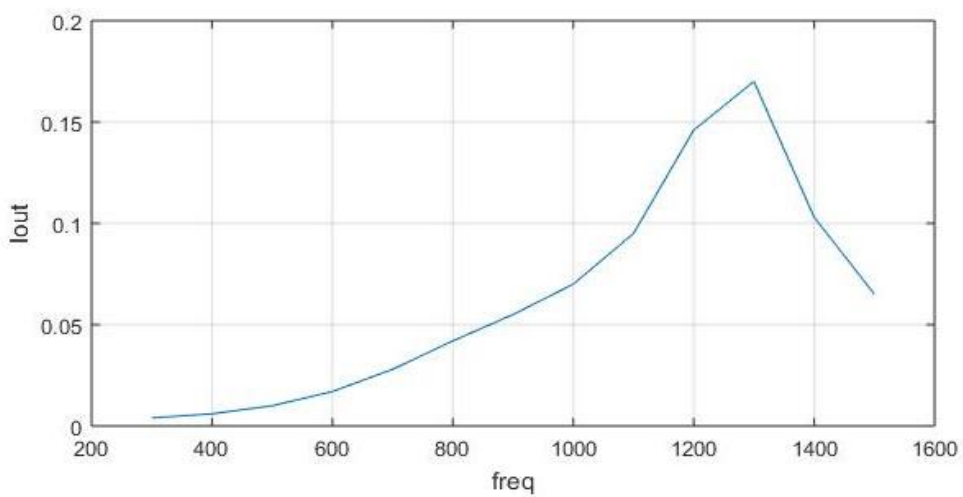


Fig. 5. Output AC voltage with frequency for MOSFET mf_phi_LF2802A_19930106

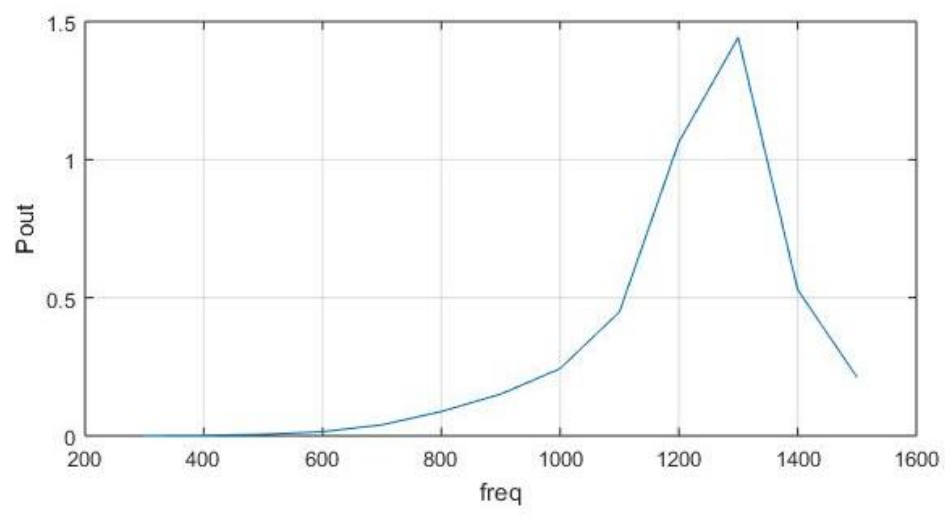

Fig. 6. Output AC power with frequency for MOSFET mf_phi_LF2802A_19930106

The second proposed circuit used,(FET_GaAs_fll101_me19931021) transistor with dc voltage sets to $V_{d c}=11 v$ While DC is measured $I_{d c}=212.3 \mathrm{~mA}$

Table (2) shows measured and calculated values for the frequency range $(300 \mathrm{MHz}-1.5 \mathrm{GHz})$ for (FET_GaAs_fll101_me19931021) transistor where figures ( 7 through 10) clarify the graphs of Efficiency, output AC current, output $\mathrm{AC}$ voltage and output $\mathrm{AC}$ power of the chosen transistor, the figures indicate that the maximum values are at the frequency $(0.8 \mathrm{GHz})$ with $\mathrm{BW}=442.6 \mathrm{MHz}$.

Table 2. Measured and calculated values for this circuit (FET_GaAs_fll101_me19931021)

\begin{tabular}{|c|c|c|c|c|c|c|c|}
\hline EFF & PDC & IDC & VDC & POUT & VOUT & IOUT & F \\
\hline $2.61208 \mathrm{E}-05$ & 2.3353 & 0.2123 & 11 & 0.000061 & 0.061 & 0.001 & 300 \\
\hline
\end{tabular}




\begin{tabular}{|c|c|c|c|c|c|c|c|}
\hline $9.50627 \mathrm{E}-05$ & 2.3353 & 0.2123 & 11 & 0.000222 & 0.111 & 0.002 & 400 \\
\hline 0.000311737 & 2.3353 & 0.2123 & 11 & 0.000728 & 0.182 & 0.004 & 500 \\
\hline 0.000734809 & 2.3353 & 0.2123 & 11 & 0.001716 & 0.286 & 0.006 & 600 \\
\hline 0.001645613 & 2.3353 & 0.2123 & 11 & 0.003843 & 0.427 & 0.009 & 700 \\
\hline 0.002581253 & 2.3353 & 0.2123 & 11 & 0.006028 & 0.548 & 0.011 & 800 \\
\hline 0.002571832 & 2.3353 & 0.2123 & 11 & 0.006006 & 0.546 & 0.011 & 900 \\
\hline 0.001807477 & 2.3353 & 0.2123 & 11 & 0.004221 & 0.469 & 0.009 & 1000 \\
\hline 0.001353145 & 2.3353 & 0.2123 & 11 & 0.00316 & 0.395 & 0.008 & 1100 \\
\hline 0.001016144 & 2.3353 & 0.2123 & 11 & 0.002373 & 0.339 & 0.007 & 1200 \\
\hline 0.00076821 & 2.3353 & 0.2123 & 11 & 0.001794 & 0.299 & 0.006 & 1300 \\
\hline 0.000575943 & 2.3353 & 0.2123 & 11 & 0.001345 & 0.269 & 0.005 & 1400 \\
\hline 0.000526699 & 2.3353 & 0.2123 & 11 & 0.00123 & 0.246 & 0.005 & 1500 \\
\hline
\end{tabular}

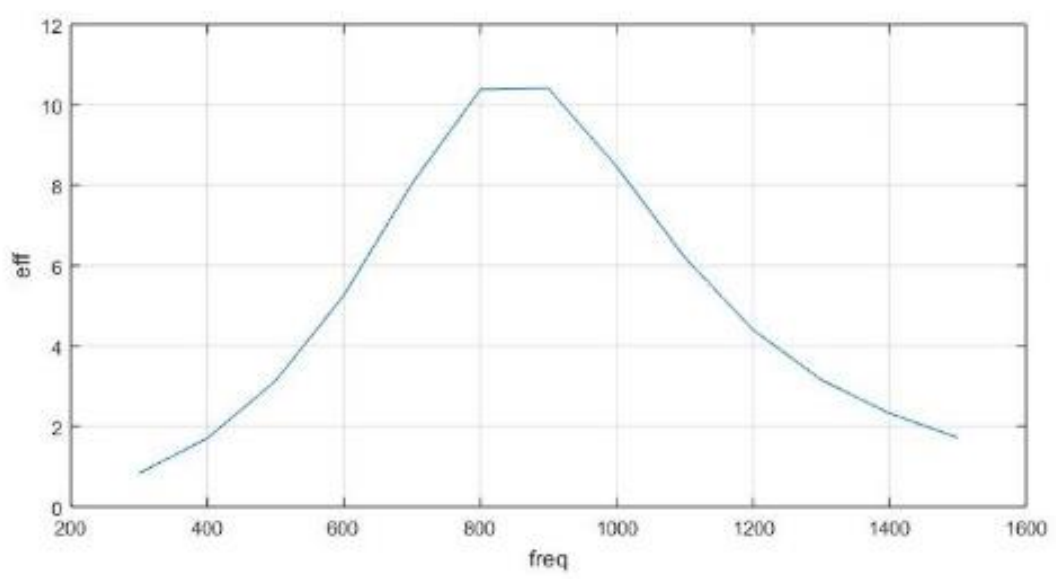

Fig. 7. Efficiency with frequency for FET_GaAs_fll101_me19931021 


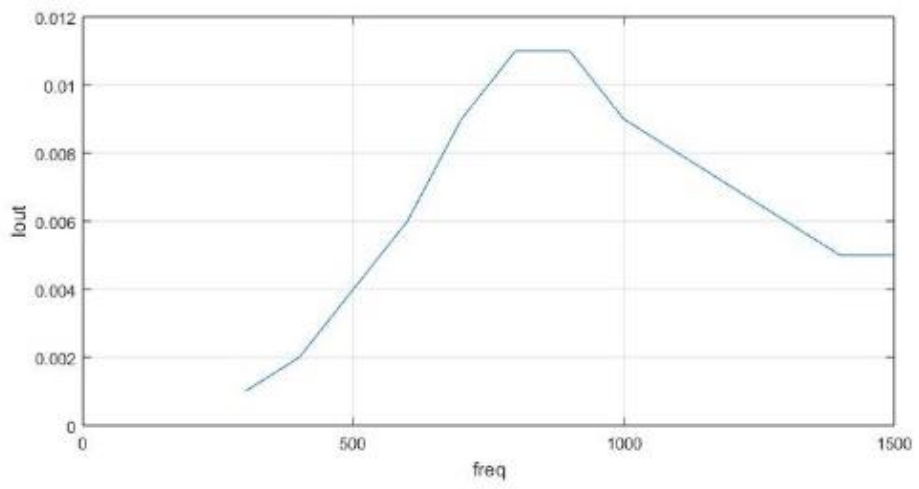

Fig. 8. Output AC current with frequency for FET_GaAs_fll101_me19931021

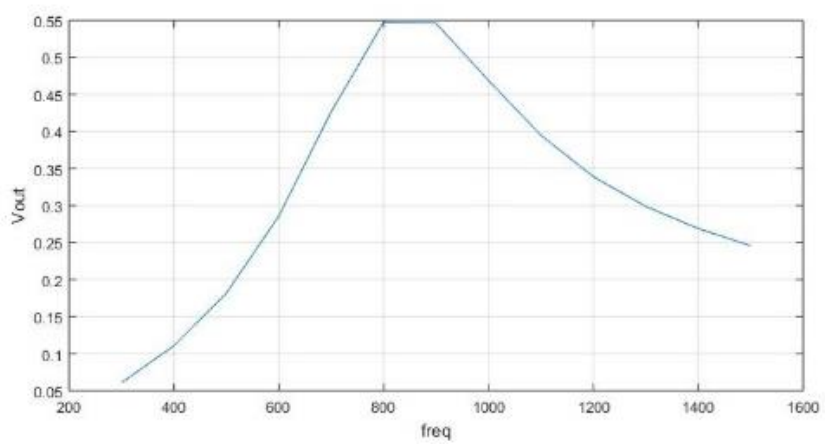

Fig. 9. Output AC voltage with frequency for FET_GaAs_fll101_me19931021

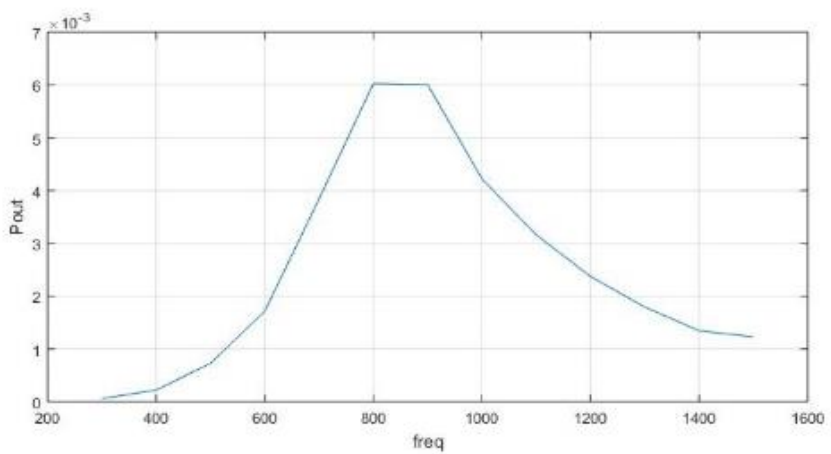

Fig. 10. Output AC power with frequency for FET_GaAs_fll101_me19931021 
The third circuit used (BJT_BC_32719961209) transistor with dc voltage sets to

$V_{d c}=11 v$

While DC is measured $I_{d c}=7.49 \mathrm{~mA}$

Table (3) shows measured and calculated values for the frequency range $(300 \mathrm{MHz}-1.5 \mathrm{GHz})$ for (BJT_BC_32719961209) transistor where figures ( 11 through 14) explain the graphs of Efficiency, output AC current, output $\mathrm{AC}$ voltage and output $\mathrm{AC}$ power of the chosen transistor, the figures indicate that the maximum values are at a frequency $(0.9 \mathrm{GHz})$ with $\mathrm{BW}=556.4 \mathrm{MHz}$.

Table 3. Measured and calculated values for this circuit (BJT_BC_32719961209)

\begin{tabular}{|c|c|c|c|c|c|c|c|}
\hline EFF & PDC & IDC & VDC & POUT & VOUT & IOUT & F \\
\hline 0.831703 & 0.08239 & 0.00749 & 11 & 0.068524 & 1.852 & 0.037 & 300 \\
\hline 1.704697 & 0.08239 & 0.00749 & 11 & 0.14045 & 2.65 & 0.053 & 400 \\
\hline 3.131157 & 0.08239 & 0.00749 & 11 & 0.257976 & 3.583 & 0.072 & 500 \\
\hline 5.255589 & 0.08239 & 0.00749 & 11 & 0.433008 & 4.656 & 0.093 & 600 \\
\hline 8.035623 & 0.08239 & 0.00749 & 11 & 0.662055 & 5.757 & 0.115 & 700 \\
\hline 10.37633 & 0.08239 & 0.00749 & 11 & 0.854906 & 6.526 & 0.131 & 800 \\
\hline 10.40813 & 0.08239 & 0.00749 & 11 & 0.857526 & 6.546 & 0.131 & 900 \\
\hline 8.46008 & 0.08239 & 0.00749 & 11 & 0.697026 & 5.907 & 0.118 & 1000 \\
\hline 6.194356 & 0.08239 & 0.00749 & 11 & 0.510353 & 5.053 & 0.101 & 1100 \\
\hline 4.398046 & 0.08239 & 0.00749 & 11 & 0.362355 & 4.263 & 0.085 & 1200 \\
\hline 3.155626 & 0.08239 & 0.00749 & 11 & 0.259992 & 3.611 & 0.072 & 1300 \\
\hline 2.32453 & 0.08239 & 0.00749 & 11 & 0.191518 & 3.089 & 0.062 & 1400 \\
\hline 1.719493 & 0.08239 & 0.00749 & 11 & 0.141669 & 2.673 & 0.053 & 1500 \\
\hline
\end{tabular}

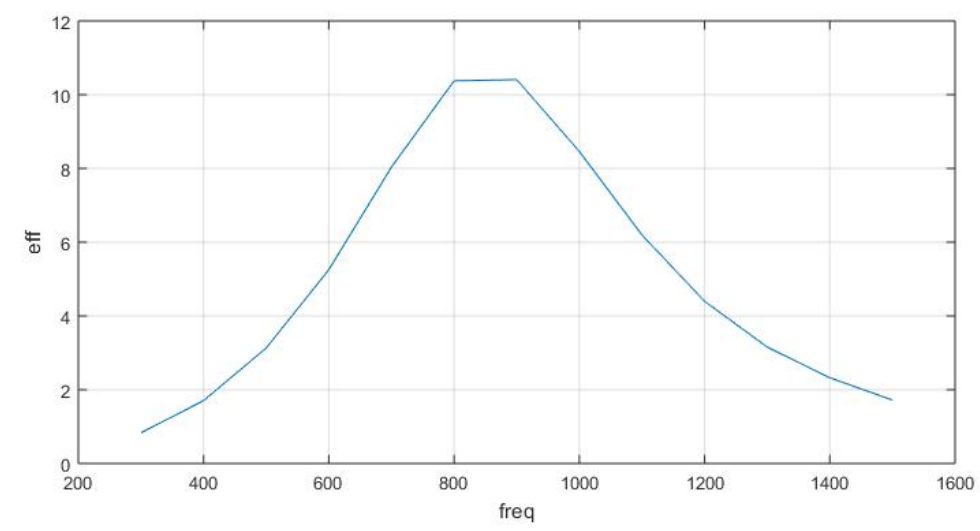

Fig. 11. Efficiency with frequency for BJT_BC_32719961209 


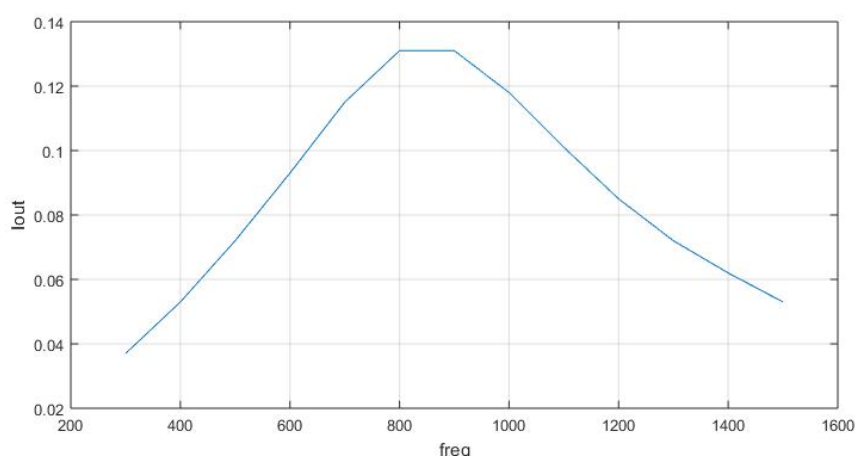

Fig. 12. Output AC current with frequency for BJT_BC_32719961209

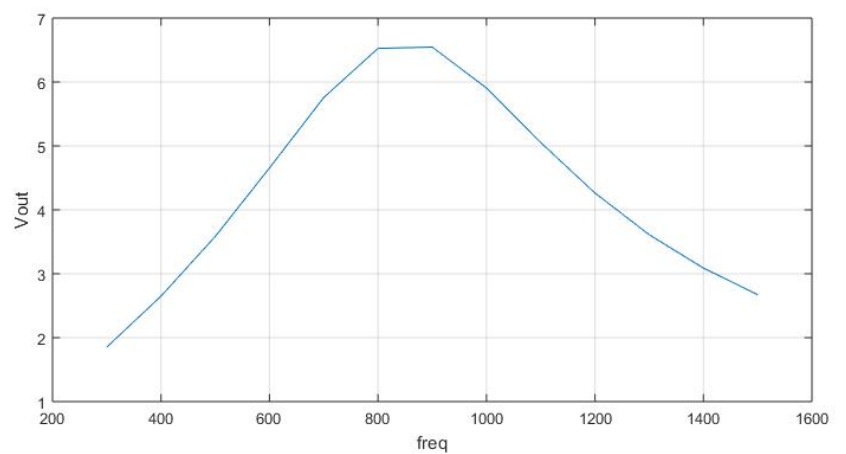

Fig. 13. Output AC voltage with frequency for BJT_BC_32719961209

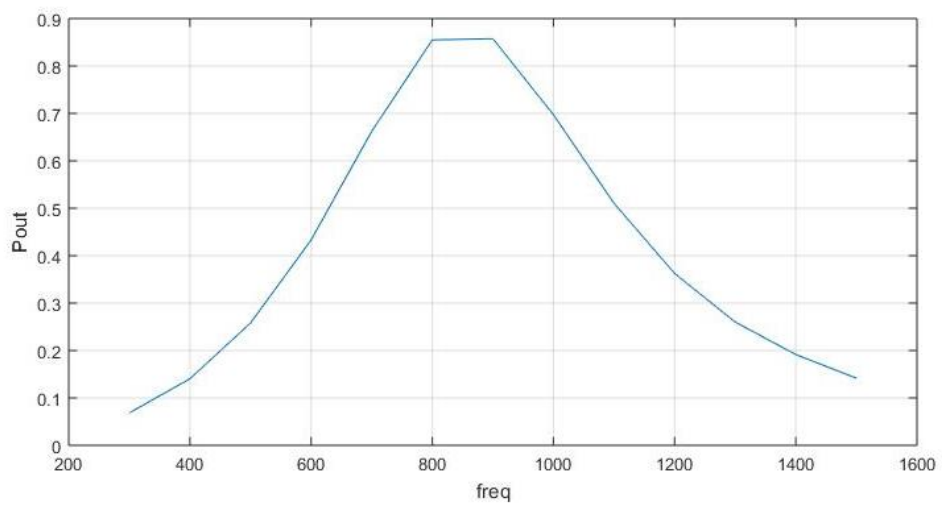

Fig. 14. Output AC power with frequency for BJT_BC_32719961209 


\section{Conclusion:}

Various types of MOSFET active devices have been presented through a design process of a E-Class power amplifier. The results concern the maximum efficiency, AC output current, AC output voltage and output power have been illustrated. MOSFET (mf_phi_LF2802A_19930106) shows a better operation at $1.3 \mathrm{GHz}$, while for, (FET_GaAs_fll101_me19931021) the maximum point is at frequency $0.8 \mathrm{GHz}$ and finally BJT_BC_32719961209 was best performed 0.9GHz. It is expected that these frequencies can be best fit the white space of terrestrial television broadcasts.

\section{References:}

1- H. R. Khan, Q. Wahab, J. Fritzin, A. Alvandpour, Q. Wahab, "A $900 \mathrm{MHz} 26.8 \mathrm{dBm}$ Differential Class-E CMOS Power Amplifier", Electronic Engineering Department, NED University of Engineering \& Technology, Karachi, Pakistan, Division of Electronic Devices, Department of Electrical Engineering, Linköping University, Linköping, Sweden, German Microwave Conference 2010.

2- Farshid Tamjid, Javad Yavand Hasani, Yasin Alekajbaf, Abdolreza Rahmati "Analysis and Design a $2.5 \mathrm{GHz}$ Class-E Power Amplifier in Two Configurations" Electrical Engineering Department Iran University of Science and Technology Tehran, Iran, $5^{\text {th }}$ Iranian Conference on Electrical and Electronic Engineering ICEEE Islamic Azad University Gonabad Branch, August 20,21,22-2013.

3- Y.Yusmarnita, S.Saat, A.H. Hamidon, H. Husin, N. Jamal, Kh. Kamarudin, I. Hindustan, "Design and Analysis of $1 \mathrm{MHz}$ Class-E Power Amplifier", Faculty of Electronics \& Computer EngineeringUniversiti Teknikal Malaysia Melaka, E-ISSN: 2224-266X WSEAS TRANSACTIONS on CIRCUITS and SYSTEMS, Volume 14, 2015.

4- Yusmarnita Yusop, ShakirSaat, Huzaimah Husin, Imran Hindustan, Sing Kiong Nguang, "Analysis of $1 \mathrm{MHz}$ Class-E Power Amplifier for Load and Duty Cycle Variations", Faculty of Electronics \& Computer Engineering, Universiti Teknikal Malaysia Melaka, Melaka, Malaysia, Department of Electrical \& Computer Engineering, the University of Auckland, New Zealand, International Journal of Power Electronics and Drive System (IJPEDS), ISSN: 2088-8694 Vol. 7, No. 2, June 2016, pp. 358 368.

5- Reza Shafaei, Mahrokh Maghsoodi, "Dual-Band High-Efficiency Class-E Power Amplifier", Department of Electrical Engineering University of Guilan, Rasht, Iran, International Journal of Advanced Research in Computer Science Software Engineering, Volume 6, Issue 4, April 2016, pp:136-140.

6- Shankar R, M.C.John Wiselin, Divya Selvathurai, "Design Simulation and Analysis of Class E Power Amplifier", Research Scholar, PRIST University, Thanjavur, Tamilnadu, India, Head and Professor/EEE, Vidya Academy of Science and Technology, Thrissur, Kerala, India, Rajalakshmi College of Engineering, Chennai, India, Shankar R et al., International Journal of Advanced Engineering Technology E-ISSN 09763945, Int J Adv Engg Tech/Vol. VII/Issue III/July-Sept.,2016/05-12.

7- R. SHANKAR1, M. C. JOHN WISELIN2, KANCHANA. D3 \& SREEJA. B. S4, "A 1GHz Class E Power Amplifier for Wireless Applications", Research Scholar, PRIST University, Thanjavur, Tamil Nadu, India, Head and Professor, EEE, Vidya Academy of Science and Technology, Trivandrum, India, Department of ECE, SSN College of Engineering, Chennai, Tamil Nadu, India, International Journal of Electrical and Electronics Engineering Research (IJEEER) ISSN (P): 2250-155X; ISSN (E): 2278-943X Vol. 7, Issue 4, Aug 2017,pp. 103-110.

8- Ayyaz Ali., Syed Waqas Haider Shah†, Khalid Iqbal, "Design of an Efficient Single-Stage and 2-Stages ClassE Power Amplifier (2.4GHz) for Internet-of-Things" Department of Electrical Engineering, Army Public College of Management \& Sciences, Rawalpindi (46000), Pakistan, Department of Electrical Engineering, Information Technology University, Lahore (54000), Pakistan, National University of Science and 
Technology, Islamabad (46000), Pakistan, International Conference on Frontiers of Information Technology (FIT), Islamabad, Pakistan, Pakistan 17-19 Dec. 2018. 